This type of article would be of greater help to the nonspecialist or paramedical staff working in the field of epilepsy. Other articles such as the one on 'dental and skeletal manifestations of anti-convulsant therapy' contain good summaries of knowledge with appropriate references and would be of value to the specialist. There are some useful articles on the social aspects of epilepsy.

This book is not one which could be used as a textbook on epilepsy as a whole but it would be most useful to have in a unit associated with patients who have epilepsy. There are articles within it of interest to a wide group of people working in this field.

\section{Functional Histology. A Text and Colour Atlas}

By P. R. Wheater, H. G. Burkitt, V. G. Daniels. Illustrated by P. J. Deakin. Pp. 278. Churchill Livingstone, Edinburgh, London and New York, 1979. £12.00 (paperback), $£ 18.00$ (hardback).

This is an ambitious book. It is aimed principally at students of medicine, dentistry, veterinary science, pharmacy and mammalian biology, but the authors cast their net wide and suggest that it could find a place in the school classroom and the pathology laboratory. The aim is supported by a choice of illustrations ranging from electron micrographs to very low power light micrographs, together with diagrams which help to build up a 3-dimensional picture.

The text which accompanies the illustrations marks an innovation in histology text books. It relates structure to function in a clear and concise manner, and draws the student's attention to aspects of biochemistry, physiology and molecular biology which are relevant to the tissues and cells illustrated. This is an exciting departure, especially since the authors have not hesitated to go to the limits of our present knowledge, indicating when some functions are obscure or giving alternative theories (for instance, the splenic circulation).

The first question one asks of such a book is: does it succeed in bringing out the functional aspects of the tissues illustrated? Here one must give a resounding Yes. For anyone who does not wish simply to learn by rote-and who does?the marriage of structure to function really works. Inevitably in order to produce a book of reasonable size, the authors have omitted or simplified some aspects of function, but on the whole they have managed to convey a remarkable amount of information. It is illuminating and instructive to turn, for example, to the histology of the stomach and to find conventional histology supplemented by electron micrographs of peptic, parietal and endocrine cells of the gastric mucosa together with a clear exposition of their function. And the same thoughtful approach to function via structure pervades the whole book.

The second question is: does it pass the test of being used as a reference book in the laboratory? Here again the answer is Yes. Most of the illustrations are of a high quality, but some of the mauves and purples have smudged in reproduction. One might also cavil at the use of so many unfamiliar stains. Nevertheless, the practising pathologist and the student of histology should find the answers to his queries here. The very low power micrographs-an admirable feature of this book-serve to orientate one, and from them one is led through higher powers to the fine points of cellular structure.

Thirdly, is it a good book to learn from? Here the authors' ambition in appealing to as wide an audience as possible may prove a defect, since some of the more obscure text could be wasted or even muddling to a beginner. But the student studying histology as part of a degree course should find it a useful handbook.

The book is well written and well illustrated, and if the joint authors are prepared to keep the text as refreshingly topical as it is at the moment one hopes that Functional Histology may become indispensable to students and a standard reference book in the pathology laboratory. It $\varrho$ certainly deserves to succeed.

Hospital-Associated Infections in the General Hospital Population and Specific Measures of Control

Edited by Dieter Gröschel. Handbook on Hospital- $\overline{\bar{\omega}}$ Associated Infections. Series vol. 3. Pp. xii +188 , illustrated. $\overparen{\triangleright}$ Marcel Dekker, New York, 1979. Sw. fr. 56,00.

The latest volume in this interesting 'Handbook' series क presents a reasonably up-to-date account of hospital infection $\overrightarrow{0}$ problems among surgical, obstetrical and medical patients. A dogmatic approach is inevitable in a book of this kind $\overrightarrow{\vec{\omega}}$ which is 'addressed to all health care personnel'; nevertheless, $\underset{\sim}{\omega}$ the text is potentially misleading in a number of instances. Thus, in the first chapter, the term 'community-acquired' infection is used to refer to endogenous hospital infection. The micro-organisms concerned may indeed have been imported from the outside world, but such terminology will inevitably lead to confusion. It is also misleading to read that 0 carriers of Staphylococcus aureus among the staff are only hazardous if they have purulent skin infection. This takes no account of the serious outbreaks of infection that have been traced to 'dispersers' among the staff who had heavy colonization of eczema and other dermatoses. Similarly, complacency 윽 is encouraged by the statement that $90 \%$ of neonates are $\rightarrow$ colonized by Staph. aureus. When the incidence rises above $\rightarrow$ about $70 \%$, outbreaks of sepsis are likely unless vigorous $\frac{7}{0}$ preventive measures are taken. Moreover, the short section on Gram-negative infections in neonates should have included $\vec{\bullet}$ a mention of the pre-eminent position of coliform ap $\infty$ Proteus bacilli in bacteraemia and meningitis in this a group. The otherwise comprehensive chapter on respirata infections summarizes the problems of cytomegalovirus immune-compromized patients, but omits any mention of varicella in such individuals, or the special dangers to the $\bar{\sigma}$ nursing staff posed by patients with herpes simplex of the oro-pharynx. Another omission is the lack of any reference $\frac{}{D}$ to Staph. epidermidis infections after insertion of hip joints or other prostheses.

Antibiotics are specified when relevant, but the recom- $\frac{0}{3}$ mendation to use the mixture of cephalothin with gentamicin $\vec{\partial}$ in severe infections should no longer be made in view of the well established risk of its nephrotoxicity, and the availability of safer and more efficacious caphalosporins. The book contains some useful summaries and guides to current 3 literature; but although printed cheaply as camera-ready $\dot{\sigma}$ typescript, without diagrams or other illustrations, its 3 price is unfortunately prohibitive when converted into sterling.

\section{Malignant Lymphoma}

Edited by R. Levy and H. S. Kaplan. Pp. 239. UICC. 을 Geneva. 1978. Sw. fr. 20.00 .

This report of a workshop on the subject of human malignant lymphoma set up by the International Union against Cancer $\mathrm{N}$ will be of considerable value to pathologists and clinicians interested in the lymphoid malignancies.

Beginning with the control of haematopoietic and lymphoid cell proliferation and ending with the effect of lymphomas on the host, this short volume contains a comprehensive review of the present state of knowledge of the aetiology and all $\mathbb{D}$ facets of the pathophysiology of the malignant lymphomas. The text is brief and to the point and each chapter is accompanied by a full set of references. Although the authors point $\bar{O}$ out in the introduction that several aspects of the subject 